\title{
Field evaluation of WHO-MDT of fixed duration at ALERT, Ethiopia: the AMFES project-I. MDT course completion, case- holding and another score for disability grading
}

\author{
A. J. DE RIJK, ${ }^{*} \ddagger$ SHIBRU GABRE, ${ }^{*}$ P. BYASS $\dagger \&$ \\ THEODROES BERHANU* \\ * All Africa Leprosy and Rehabilitation Training Centre (ALERT), \\ PO Box 165, Addis Ababa, Ethiopia; †Department of Public Health \\ Medicine and Epidemiology, University of Nottingham, Queen's \\ Medical Centre, Nottingham, UK
}

\section{Accepted for publication 9 March 1994}

\begin{abstract}
Summary We report on 286 new leprosy patients (128 PB, $158 \mathrm{MB}$ ) enrolled in the AMFES project, a field study in which patients are monitored during WHOMDT and during 5 years thereafter, by active surveillance. This first paper describes the purposes, organization and methods of the study, patient enrolment and preliminary results of MDT completion and case-holding.

Of $128 \mathrm{~PB}$ patients $102(79 \cdot 7 \%)$ completed MDT and of 91 on surveillance for more than 1 year, coverage with reviews had been good or very good for 31 , fair or poor for 36 and very poor or nil for $21 \mathrm{~PB}$ patients. Of $158 \mathrm{MB}$ patients 64 had completed MDT, and 26/128 (20.3\%) PB and 18/158 (11.4\%) MB patients were lost to follow-up during treatment, with $76 \mathrm{MB}$ patients still on treatment.

At first diagnosis, 159/286 (55.6\%) had nerve function impairment, with no significant differences in disability grade by gender or between PB and MB patients. The proportion of disability grade 0 amongst new cases decreased very significantly with age, from $28 / 41(68 \cdot 3 \%)$ for age $0-14$ years to $13 / 57(22 \cdot 8 \%)$ for 50 years and above. In view of the limitations of patient disability grades, a score per patient of the sum of disability grades for the four extremities, named 'HF-impairment score', is shown to be more informative.

Incidence of leprosy reactions and neuritis in these patients, during treatment and during surveillance, is reported upon in Part II (on pp. 320-332 of this issue).
\end{abstract}

\section{Introduction}

In order to evaluate the effectiveness of the WHO-recommended multidrug therapy (MDT) regimens ${ }^{1}$ in the operational conditions of a leprosy control programme, ALERT's MDT Field Evaluation Studies (the AMFES project) started patient intake in 1988. The

‡ Correspondence: c/o SNV, Netherlands Development Organisation, PO Box 40675, Addis Ababa, Ethiopia. 
main objectives are to assess: the incidence of relapse and factors associated with the occurrence of relapse; the incidence of leprosy reactions and factors associated with the occurrence of reactions; and the incidence of new or increased nerve dysfunction and its progression to permanent nerve function impairment.

In this long-term prospective study, paucibacillary (PB) and multibacillary (MB) patients are observed for reactions and nerve dysf unction during the course of MDT and for reactions, nerve dysfunction and relapse occurring after the course of MDT during a 5-year period of active surveillance.

Observations are made under routine leprosy control service conditions. Criteria for diagnosis, for allocation to categories $\mathrm{PB}$ and $\mathrm{MB}$, for relapse, reaction, nerve dysf unction and also the treatment regimens used, are all similar to those in the routine leprosy control services. ${ }^{2}$

Enrolment started in April 1988. This paper gives findings up to the end of June 1992, for 286 new patients registered in the first 3 years of the project, who had been observed for between 15 and 51 months. Characteristics of patients are given and results to date regarding completion of MDT courses and changes in BI during MDT. For 102 PB patients who completed MDT, we give preliminary results of case holding during up to 3 years of active surveillance.

A second paper (Part II, pp. 320-332) gives preliminary findings on the incidence of leprosy reactions, neuritis and nerve dysfunction in this cohort of patients.

\section{Methods}

In the absence of active case detection, practically all patients enter the control programme as self-reporting new cases at one of the 99 leprosy clinics held in the area. ALERT's leprosy control programme is essentially still a vertical leprosy service run by specialized health personnel. All new, untreated leprosy patients are eligible for enrolment. Thirty-nine patients who had received some dapsone just before the start of their MDT treatment for a short period only (for up to 8 weeks for PB and 16 weeks for MB) have also been regarded as 'new, untreated'. Apart from that small amount of preMDT dapsone these patients did not differ from the others.

\section{DIAGNOSIS AND CLASSIFICATION}

Seven leprosy control supervisors (LCSs) carry out the diagnosis and classification of the patients. These LCSs are paramedical health workers with additional special training in leprosy. All have many years of experience in leprosy work in peripheral clinics. Their work was supervised by two medical officers (MOs) (AdR and SG), who confirmed diagnosis, classification and eligibility for enrolment on the basis of the patient record cards which the LCSs presented to the MOs within 2-4 weeks of the first examination.

Paucibacillary (PB) patients are those clinically classified as tuberculoid (TT), borderline tuberculoid (BT) or indeterminate (I) and who have or had a negative bacterial index (BI) at all sites. Until July 1989, BT patients whose highest BI $=1$ were included in the PB group. Multibacillary (MB) patients are those clinically classified as borderline-tuberculoid (BT) with positive skin smears, borderline-lepromatous (BL) or lepromatous (LL) and all those who have, or had at any time, a positive skin smear at one or more sites. 
ALERT's field programme, and thus also this study, uses the simplified classification for fieldworkers recommended by Jopling which adds the rarely occurring BB cases to the BL group. ${ }^{3}$ The term neural leprosy (NL) is used for leprosy patients with nerve involvement only, lacking skin lesions and whose skin smears are (repeatedly) negative, there is either clear thickening of more than one peripheral nerve with or without functional loss, or at least one clearly thickened nerve with some associated loss of function. For these NL patients, assignment of treatment regimen (PB or MB) was based on the extent of nerve involvement or on the finding of acid-fast bacilli in a nerve biopsy.

For the majority of patients clinical diagnosis and classification posed no problems to the LCSs. Skin smears were taken, for all patients, from both earlobes and from at least two skin lesions. In case of doubt on a paucibacillary condition (advanced BT or BL?), skin smears were repeated after 4 or 8 weeks. If, for patients clinically classified as $\mathrm{BL}$ or LL, the first smear results were negative, skin smears were to be repeated and, if the BI was again found to be zero, the patient was examined by one of the MOs who also performed a skin biopsy. In case of doubt in classification between BT and BL, the LCSs were instructed to start treatment with the MDT regimen for PB patients while awaiting the skin-smear results and, if necessary, the assessment by one of the MOs. The following combinations of findings made a re-examination by an MO for diagnosis or classification necessary:

patients clinically $\mathrm{BL}$ or $\mathrm{LL}$, for whom the highest $\mathrm{BI}<2$ in two consecutive sets of skin smear examinations;

patients clinically BT, with any skin smear positivity;

patients clinically classified as TT or indeterminate (I);

patients clinically assessed as BT, with no definite sensory loss for light touch in skin lesions; and

patients with negative skin smears and in whom no leprosy-like skin lesions have been seen and who thus should have either neural leprosy or no (active) leprosy.

The MO, when re-examining the patient, usually takes a skin biopsy. Skin biopsies are also taken in other recently registered patients when seen by an MO during a routine supervisory clinic visit. Where the histopathologist's assessment of the classification differs from the classification given on clinical assessment, this does not usually lead to a change of the classification or of the treatment regimen. This is because we aim at an evaluation of the MDT programme under field conditions. In ALERT's field services no biopsies are usually taken for the sake of classification. Therefore, it is only in cases where the MO cannot, on clinical examination including repeated skin smears, draw a conclusion, that the histopathologist's classification is taken into account for the final decision.

\section{TREATMENT}

For PB patients, treatment consists of self-administered dapsone $100 \mathrm{mg}$ daily $(50 \mathrm{mg}$ for patients under 15 years) for 27 days, plus that dapsone dose and rifampicin $600 \mathrm{mg}$ (300 mg for patients under 15 years) given under supervision once every 4 weeks, at the time of drug collection. The treatment course is completed when 6 doses of rif ampicin have been taken within a period of $(9 \times 4=) 36$ weeks.

Treatment for MB patients consists of $100 \mathrm{mg}$ dapsone $+300 \mathrm{mg}$ clofazimine $+600 \mathrm{mg}$ 


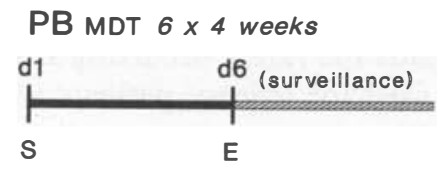

dn: MDT for $n^{\text {th }}$ 28-day period

R: review

S: skin smear

$E$ : end of MDT

\section{MB MDT $26 \times 4$ weeks}

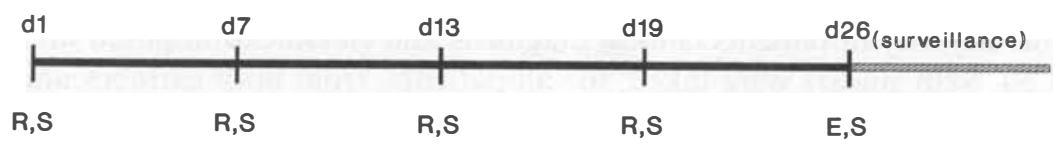

PB \& MB surveillance

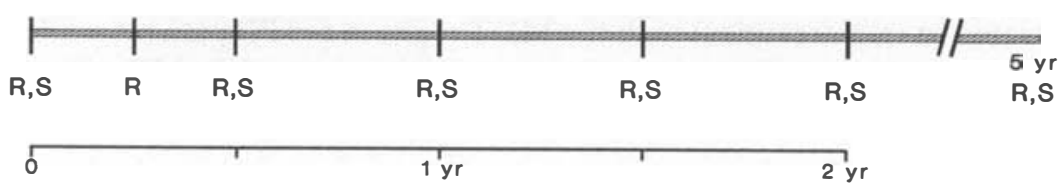

Figure 1. Timetable for MDT and surveillance of $\mathrm{PB}$ and $\mathrm{MB}$ patients, with reviews and skin-smear examinations, in the AMFES project. Surveillance follows the same pattern throughout the 5-year period after completion of MDT. During surveillance skin smears are taken from MB patients at every 6-monthly review and from $\mathrm{PB}$ patients only when clinical activity is observed at a review.

rifampicin once in 4 weeks, given under supervision on the day of drug collection, and 50 mg clofazimine $+100 \mathrm{mg}$ dapsone for daily self-administration over 27 days. For children the dosages are adjusted. For MB patients the duration of the MDT course is fixed, limited to 2 years $(26 \times 4$ weeks of drug supply within a period of up to 3 years), regardless of the BI found in skin smears, while routine leprosy services in Ethiopia follow WHO's 1982 recommendation ${ }^{1,2}$ by which the MDT treatment of MB patients is continued until skin smear negativity. Time schedules of MDT for PB and MB patients are summarized in Figure 1.

Since 1990, blister-calendar packs have been in use. In areas where either the patient or the health personnel (or both) cannot reach the treatment point during the rainy season, 4-5 blister packs are given at one time to cover the period of inaccessibility. Thus, for about $30 \%$ of the patients, 3-4 of the 134 -weekly doses per year were given unsupervised.

Drug collections are recorded in treatment registers kept at each clinic. Compliance with drug intake is assessed by urine testing for dapsone at drug collections 1,3 and 6 for patients on the PB regimen, and at drug collections 1, 3, 7, 13, 19 and 25 for MB patients.

At every 4-weekly drug collection each patient is briefly examined by the clinic's health assistant, who tests for changes in muscle strength of eyelids, hands and feet by a standard set of voluntary muscle tests (VMT) and changes in the sensitivity of eyes, palms and soles by sensory testing (ST).

All patients are also periodically examined by the LCSs. For PB patients at the 6th treatment round, before the treatment course will be completed. MB patients are 
reviewed at treatment rounds $7,13,19$ and 25 or 26 . At each of these review examinations (Figure 1), the LCS assesses the skin lesions, takes skin smears from 4 sites, does all routine nerve function tests and records the findings on the patient record card.

\section{CASE HOLDING}

During treatment, case holding is promoted by individual health education on the importance of regular drug collection and faithful drug intake. When a patient is absent, our staff ask other patients about the absentee. If still absent at the next scheduled MDT clinic, action must be taken to get her/him back to treatment. If using other patients as messengers and motivators does not work, the defaulting patient should be visited at home by the health assistant of the clinic. Not all absent patients are visited at home. In some cases the patient's home is inaccessible to the health worker concerned. From the beginning of 1991 until July 1992, the feasibility of home visiting was further reduced, in several areas, due to poor security.

PB patients who have not taken the prescribed 6 doses of supervised treatment within 9 months (36 weeks), and MB patients who have not received 26 supervised doses of their regimen within a period of 3 years, are recorded as 'treatment not completed' $(\mathrm{TnC})$, and excluded from the relapse study. For the incidence of reactions, neuritis or nerve dysfunction, these patients participate in the study for as long as they attend for treatment.

\section{SURVEILLANCE}

A surveillance register is kept and patients are appointed for review at 3 and 6 months after completion of the MDT course and thereafter twice yearly at intervals of 6 months (periods of 6 or $7 \times 4$ weeks; Figure 1).

Case-holding action during this active surveillance is basically the same as during the treatment phase. The surveillance period for both MB and PB patients is 5 years.

\section{QUALITY CONTROL AND DATA MANAGEMENT}

The MOs check the cards of all patients once every 4 weeks to supervise timely and accurate data collection, and then write reminder slips for the LCSs, indicating what needs be done next. They also make supervisory visits to clinics according to plans issued every 8 weeks.

Information collected on cards and forms is entered regularly in computerized data files, usually every 4 weeks and at least once in 3 months. From October 1991 onward, all data have been entered twice and compared, to minimize entry errors. The computer is also used for quality control on the LCS's records. Two stages of validation programs identify impossible or unlikely data and inconsistencies, so that recording errors can often be found and corrected before new data are appended to the master file. ${ }^{4}$

Statistical comparisons of numeric quantities have been made by calculating $95 \%$ confidence intervals (CIs) of differences between means. Thus a statistical difference exists when the $95 \%$ CI excludes zero. 
Table 1. Enrolment of patients in the first 3 years of AMFES: Classification, sex and age distribution at intake

\begin{tabular}{|c|c|c|c|c|c|c|c|c|c|c|}
\hline \multirow{3}{*}{$\begin{array}{r}\text { Classification: } \\
\qquad \text { Sex: }\end{array}$} & \multirow{2}{*}{\multicolumn{2}{|c|}{$\begin{array}{l}\mathrm{PB} \\
\mathrm{BT}^{*}\end{array}$}} & \multicolumn{6}{|c|}{ MB } & & \\
\hline & & & \multicolumn{2}{|c|}{ BT } & \multicolumn{2}{|c|}{$\mathrm{BL} \dagger$} & \multicolumn{2}{|c|}{ LL } & \multicolumn{2}{|c|}{ All } \\
\hline & $\mathbf{M}$ & $\mathrm{F}$ & $\mathbf{M}$ & $\mathrm{F}$ & M & $\mathrm{F}$ & $\mathbf{M}$ & $\mathrm{F}$ & $\mathbf{M}$ & $\mathrm{F}$ \\
\hline \multicolumn{11}{|l|}{ Age group (yrs) } \\
\hline $0-14$ & 10 & 12 & 1 & 1 & 7 & 4 & 5 & 1 & 13 & 6 \\
\hline $15-29$ & 25 & 25 & 1 & 0 & 32 & 6 & 16 & 7 & 9 & 13 \\
\hline $30-49$ & 13 & 10 & 1 & 3 & 25 & 13 & 7 & 4 & 33 & 20 \\
\hline$\geq 50$ & 19 & 14 & 2 & 0 & $9+$ & 6 & 7 & 0 & 18 & 6 \\
\hline All & $67^{*}$ & 61 & 5 & 4 & $73 \dagger$ & 29 & 35 & 12 & 113 & 45 \\
\hline Total & \multicolumn{2}{|c|}{$128^{*}$} & \multicolumn{2}{|c|}{9} & \multicolumn{2}{|c|}{$102 \dagger$} & \multicolumn{2}{|c|}{47} & \multicolumn{2}{|c|}{158} \\
\hline
\end{tabular}

* Including 2 TT (males aged $10 \& 67 \mathrm{yrs}$ ) and 1 NL (male aged $28 \mathrm{yrs}$ ).

$\dagger$ Including 1 NL patient.

\section{Patients and results}

We report on 286 patients, $128 \mathrm{~PB}$ and $158 \mathrm{MB}$, enrolled in the first 3 years of the project. Classification, gender and age distribution at intake, for treatment categories PB and $\mathrm{MB}$, are given in Table 1.

The two most common classifications were BT and BL. Both TT and pure NL were rarely seen, in this series each in 2 patients only. For convenience of presentation, the 2 TT patients and the paucibacillary NL patient have in the tables been included in the BT group, the other NL patient in the BL group. For the PB patients the male:female ratio was $67: 61$ or $1 \cdot 1: 1$. For the $\mathrm{MB}$ patients that ratio was $113: 45$, or $2 \cdot 5: 1$. At registration, 41 patients $(14 \cdot 3 \%)$ were in the age group $0-14$ years. The youngest was 4 years. The overall mean ages of $\mathrm{PB}$ and $\mathrm{MB}$ patients were not significantly different.

Changes of classification and/or treatment were recorded for 15 patients as shown in Table 2.

Table 2. Patients in the AMFES project whose initial classification and/or treatment category were changed

\begin{tabular}{lcc}
\hline $\begin{array}{l}\text { No. of } \\
\text { Patients }\end{array}$ & Classification & Treatment \\
\hline 2 & $\mathrm{TT} \rightarrow \mathrm{BL}$ & $\mathrm{PB} \rightarrow \mathrm{MB}$ \\
2 & $\mathrm{BT}$ & $\mathrm{PB} \rightarrow \mathrm{MB}$ \\
3 & $\mathrm{BT} \rightarrow \mathrm{BL}$ & $\mathrm{PB} \rightarrow \mathrm{MB}$ \\
4 & $\mathrm{BL} \rightarrow \mathrm{BT}$ & $\mathrm{MB}$ \\
2 & $\mathrm{LL} \rightarrow \mathrm{BL}$ & $\mathrm{MB}$ \\
1 & $\mathrm{TT} \rightarrow \mathrm{BT}$ & $\mathrm{PB}$ \\
1 & $\mathrm{BL} \rightarrow \mathrm{BT}$ & $\mathrm{MB} \rightarrow \mathrm{PB}$ \\
15 & 13 changes & 8 changes \\
\hline
\end{tabular}


Table 3. Disability grade for AMFES patients at the start of MDT, by treatment, classification and age group. Percentages for each group are shown in parentheses

\begin{tabular}{|c|c|c|c|c|c|c|c|c|c|c|}
\hline & \multirow{2}{*}{$\frac{\mathrm{PB}}{\mathrm{BT}^{*}}$} & \multicolumn{4}{|c|}{ MB } & \multicolumn{4}{|c|}{ Age groups } & \multirow{2}{*}{$\begin{array}{c}\text { Overall } \\
\text { Total }\end{array}$} \\
\hline & & BT & $\mathrm{BL} \dagger$ & LL & All & $0-14$ & $15-29$ & $30-49$ & $\geq 50$ & \\
\hline \multicolumn{11}{|c|}{ Disability grade } \\
\hline 0 & $\begin{array}{c}58 \\
(45 \cdot 3)\end{array}$ & $\begin{array}{c}2 \\
(22 \cdot 2)\end{array}$ & $\begin{array}{c}43 \\
(42 \cdot 2)\end{array}$ & $\begin{array}{c}24 \\
(51 \cdot 1)\end{array}$ & $\begin{array}{c}69 \\
(43 \cdot 7)\end{array}$ & $\begin{array}{c}28 \\
(68 \cdot 3)\end{array}$ & $\begin{array}{c}58 \\
(51 \cdot 8)\end{array}$ & $\begin{array}{c}28 \\
(36 \cdot 8)\end{array}$ & $\begin{array}{c}13 \\
(22 \cdot 8)\end{array}$ & $\begin{array}{c}127 \\
(44 \cdot 4)\end{array}$ \\
\hline 1 & $\begin{array}{c}32 \\
(25 \cdot 0)\end{array}$ & $\begin{array}{c}5 \\
(55 \cdot 5)\end{array}$ & $\begin{array}{c}29 \\
(28 \cdot 4)\end{array}$ & $\begin{array}{c}17 \\
(36 \cdot 2)\end{array}$ & $\begin{array}{c}51 \\
(32 \cdot 3)\end{array}$ & $\begin{array}{c}4 \\
(9 \cdot 8)\end{array}$ & $\begin{array}{c}29 \\
(25 \cdot 9)\end{array}$ & $\begin{array}{c}21 \\
(27 \cdot 6)\end{array}$ & $\begin{array}{c}29 \\
(50 \cdot 9)\end{array}$ & $\begin{array}{c}83 \\
(29 \cdot 0)\end{array}$ \\
\hline 2 & $\begin{array}{c}38 \\
(29 \cdot 7)\end{array}$ & $\begin{array}{c}2 \\
(22 \cdot 2)\end{array}$ & $\begin{array}{c}30 \dagger \\
(29 \cdot 4)\end{array}$ & $\begin{array}{c}6 \\
(12 \cdot 8)\end{array}$ & $\begin{array}{c}38 \\
(24 \cdot 1)\end{array}$ & $\begin{array}{c}9 \\
(22 \cdot 0)\end{array}$ & $\begin{array}{c}25 \\
(22 \cdot 3)\end{array}$ & $\begin{array}{c}27 \\
(35 \cdot 5)\end{array}$ & $\begin{array}{c}15 \\
(26 \cdot 3)\end{array}$ & $\begin{array}{c}76 \\
(26 \cdot 6)\end{array}$ \\
\hline Total & $128^{*}$ & 9 & $102 \dagger$ & 47 & 158 & 41 & 112 & 76 & 57 & 286 \\
\hline
\end{tabular}

*All BT patients except 2 TT (1 grade 0,1 grade 1$)$ and 1 NL (grade 0$)$.

$\dagger$ Including one NL patient.

\section{DISABILITY GRADING}

It is common practice in the statistics of both WHO and ILEP to grade a patient's overall disability by the highest grade recorded for anyone of that patient's eyes, hands or feet. Disability grades on this basis, at the start of MDT, are in Table 3. Overall disability grades did not differ significantly between PB and MB patients $\left(\chi^{2}=2 \cdot 2,2 \mathrm{df}\right)$. Although LL patients tended to have lower grades than other MB patients, this difference was also not significant $\left(\chi^{2}=4 \cdot 7,2 \mathrm{df}\right)$.

The differences between the four age groups (Table 3 ) in the proportions of disability grade 0 are highly significant $\left(\chi^{2}=24 \cdot 5,3 \mathrm{df}, p<0 \cdot 00002\right)$ : much larger proportions of disability grade 0 (patients without any functional impairment or deformity) were found in younger patients.

\section{OTHER SCORES FOR DISABILITY}

The WHO disability grading ${ }^{5}$ for patients, given in Table 3 , though widely used in the patient statistics of leprosy control programmes, has the great disadvantage that it does not distinguish at all between vast differences in conditions of patients. A patient who has lost one small part of one finger is given the same grading 2 as another patient who had gone blind and lost most of both hands and feet.

The AMFES project aims at developing scoring systems and indicators for physical impairment and deformity, which should be more appropriate for monitoring and evaluation of disability prevention in leprosy control programmes. Without yet having made a definite choice for any of various possible scores, we present here the condition of patients at the time of enrolment expressed as the sum of the disability grades of 2 hands and 2 feet. As each hand and each foot can be graded as either 0,1 or 2 , the sum for the 4 extremities ranges from 0 to 8 .

In our patient population it appeared to be justifiable to leave the disability grade for eyes out of this indicator. Only 6 of the $128 \mathrm{~PB}$ patients and 8 of the $158 \mathrm{MB}$ patients, 
Table 4. Disability as sum of the grades for four extremities (HF-impairment score) against disability grade per patient (highest of all 6 grades), for 286 AMFES patients

\begin{tabular}{|c|c|c|c|c|c|c|c|c|c|c|}
\hline HF-impairment score & 0 & 1 & 2 & 3 & 4 & 5 & 6 & 7 & 8 & Total \\
\hline Disability grade & & & & & & & & & & \\
\hline 0 & 127 & - & - & - & - & - & - & - & - & 127 \\
\hline 1 & - & 18 & 36 & 17 & 12 & - & - & - & - & 83 \\
\hline 2 & $1^{*}$ & - & 11 & 17 & 12 & 14 & 9 & 6 & 6 & 76 \\
\hline Total & 128 & 18 & 47 & 34 & 24 & 14 & 9 & 6 & 6 & 286 \\
\hline
\end{tabular}

* This patient had a disability grade of 2 for 1 eye, with normal hands and feet.

about $5 \%$ in all (14/286), had some disability of 1 or 2 eyes (range of score: $1-4$; mean = $2 \cdot 1)$ and all but $1^{*}$ of those 14 patients had already reached scores ranging from 2 to 8 $($ mean $=4 \cdot 7)$ for the sum of disability grades for the 4 extremities. Using a scale from 0 to 12 , with the eye condition included, would thus appear not to be of much advantage. Only 3 of the 286 patients would reach a score above $8 ; 2$ of the 14 patients with eye disability would have their scores increased from 7 or 8 to 10 and 1 from 8 to 12 .

In Table 4 this score for impairment of hands and feet (HF-impairment score) is shown against the conventional patient disability grade for all patients at the start of MDT. The table shows that of 83 patients with disability grade 1,18 patients $(21 \cdot 7 \%)$ had only 1 extremity affected, $36(43 \cdot 4 \%)$ had sensory loss in 2 extremities, $17(20 \cdot 5 \%)$ in 3 , and 12 patients $(14.5 \%)$ had all 4 extremities affected. Further, that of 76 patients with disability grade 2 , at least $12(15.8 \%)$, with HF-impairment scores 7 or 8 , had all 4 extremities affected. In tables for PB and MB patients separately (data not shown) these patterns were very similar. The mean score for patients with disability grade $2(4 \cdot 41)$ was significantly higher than for grade $1(2 \cdot 28)(95 \%$ CI for difference of means $1 \cdot 7$ to $2 \cdot 6)$.

\section{BACTERIAL INDEX (BI)}

As the BI for a patient at start of treatment, we record not the average but the highest BI found in any skin smears taken in the first 3 months of treatment. In the period before July 1989, we prescribed PB treatment regimens for 3 patients with classification BT and $\mathrm{BI}=1$. All other $\mathrm{PB}$ patients always had negative skin smears.

BIs at start for the $158 \mathrm{MB}$ patients are shown in Table 5. The BI at time of diagnosis has an inverse relationship with the HF-impairment score. This is shown in Figure 2. The mean HF-impairment score of $158 \mathrm{MB}$ patients was significantly inversely related to the $\mathrm{BI}$ (one-way analysis of variance, 6df, $p=0.0005$ ). Patients with a high $\mathrm{BI}$ at the start of treatment had on average much less physical impairment than those with lower BIs.

TREATMENT COMPLETION AND LOSS TO FOLLOW UP

Of the 128 PB patients, $102(79 \cdot 7 \%)$ completed and $26(20 \cdot 3 \%)$ patients did not complete the MDT course. Among the latter, 12 were from 1 district (Jibat na Mecha) where $42.9 \%$ of $28 \mathrm{~PB}$ patients did not complete the course. This district was worst affected by

* This patient's eye condition was almost certainly not related to leprosy. 
Table 5. Bacterial Index (BI) at start of MDT in $158 \mathrm{MB}$ patients in the AMFES project, by classification

\begin{tabular}{lrrrr}
\hline & BT & BL & LL & Total \\
\hline Highest BI & & & & \\
0 & 5 & 7 & - & 12 \\
1 & 2 & 6 & - & 8 \\
2 & 2 & 19 & - & 21 \\
3 & - & 19 & 1 & 20 \\
4 & - & 29 & 3 & 32 \\
5 & - & 15 & 20 & 35 \\
6 & - & 7 & 23 & 30 \\
& 9 & 102 & 47 & 158 \\
\hline
\end{tabular}

the internal war in 1990-91, and in some areas experienced a subsequent period of insecurity, which, we assume negatively influenced the local treatment completion rate.

The mean initial HF-impairment score for PB patients completing treatment was $1 \cdot 8$, compared with $2 \cdot 1$ for those not completing; this difference is not significant.

By the end of June 1992, 64 of the 158 patients on the MB treatment regimen had completed their MDT course, 18 patients had dropped out and 76 were still on treatment. The 18 patients lost were: 1 death, 1 transfer out to another district, 3 patients had left the area without a transfer, 10 patients had been declared out of control, of whom 4 had refused further treatment, and 3 patients had been so irregular that they did not reach an intake of 26 'doses' within 3 years and were recorded as ' $\mathrm{TnC}$ '.

Table 6 shows patient attendance rates for the 64 who had completed MDT by the end of June 1992. These figures represent a positive selection of regular patients. For the

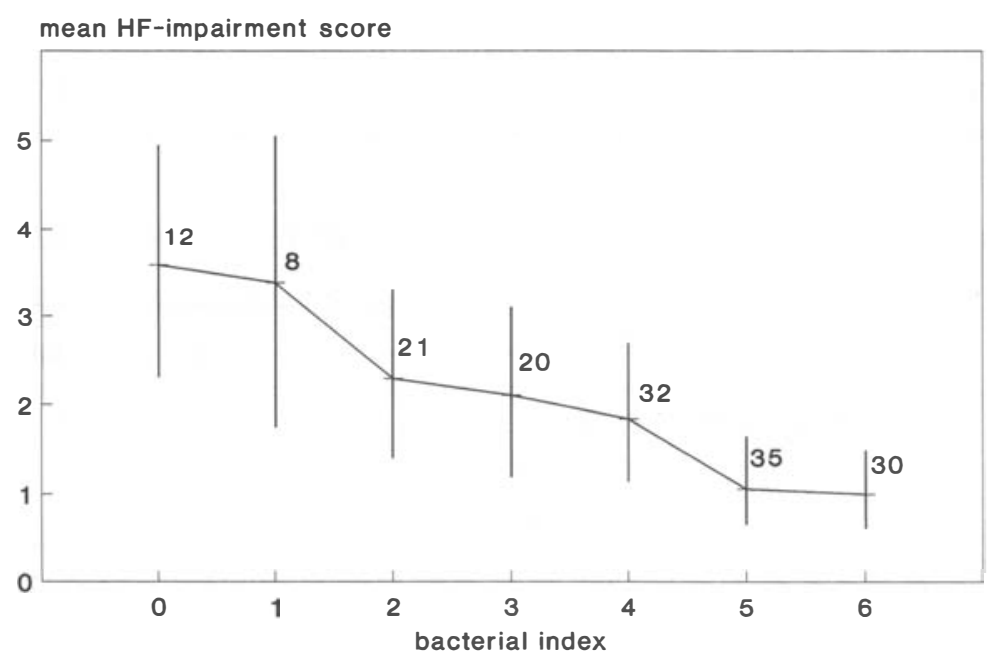

Figure 2. Relation between BI at start of MDT and mean initial disability score ('HF-impairment score') for $158 \mathrm{MB}$ patients in the AMFES project. 
Table 6. Treatment regularity of $64 \mathrm{MB}$ patients in the AMFES project who completed MDT

\begin{tabular}{ccc}
\hline $\begin{array}{c}\text { Regularity } \\
(\%)\end{array}$ & $\begin{array}{c}\text { Attendance } \\
\text { rate* at RFT }\end{array}$ & Patients \\
\hline 100 & $26 / 26$ & 33 \\
$81-99$ & $26 / 27-32 \dagger$ & 25 \\
$66-80$ & $26 / 33-35$ & 5 \\
$<66$ & $26 / 41 \ddagger$ & 1 \\
& & 64 \\
\hline
\end{tabular}

\footnotetext{
* Number of 4-weekly MDT collections/number of 4-week periods the MDT course has lasted.

† Including 7 patients who erroneously got 27,28 or 29 doses.

$\ddagger$ Exceptionally allowed beyond 39 periods of 4 weeks.
}

76 patients still on treatment, regularity of drug collection was assessed from recent computer entries of reviews and from data in treatment registers. For 4 there was no upto-date information when we completed these assessments (31 October 1992). Regular, with an attendance of $80 \%$ or more, were $52 / 72(72 \cdot 2 \%)$ patients; for 10 the attendance was fair (60-79\%), for another 10 poor to very poor.

From this analysis of the 76 patients still on treatment at the end of June 1992, we estimate that $60 / 76(78.9 \%)$ are likely to complete their MDT course. If we add the other 16 patients to the 18 already reported as dropped out, the loss from the study during the treatment phase would come to $34(21 \cdot 5 \%)$ of the $158 \mathrm{MB}$ patients. This is similar to the $26 / 128(20 \cdot 3 \%)$ for the PB patients.

\section{BI CHANGE DURING TREATMENT}

For the $64 \mathrm{MB}$ patients who completed the MDT course, Table 7 gives the highest BI of skin smears at the end of the MDT course, against the highest BI at start of MDT. Of 59 patients who started treatment with a $\mathrm{BI} \geq 2,29$ became negative; and for 57 patients (59-2 unknown), the mean of the highest BIs came down from $4 \cdot 3(\mathrm{sd} \mathrm{1 \cdot 3)}$ at the start to

Table 7. Highest BI in skin smears at start and at end of the MDT course, for 64 MB patients in the AMFES project

\begin{tabular}{|c|c|c|c|c|c|c|c|c|c|}
\hline BI at end & 0 & 1 & 2 & 3 & 4 & 5 & 6 & (Unk) & Total \\
\hline \multicolumn{10}{|l|}{ BI at start } \\
\hline 0 & 4 & - & - & - & - & - & - & - & 4 \\
\hline 1 & 1 & - & - & - & - & - & - & - & 1 \\
\hline 2 & 7 & - & 1 & - & - & - & - & - & 8 \\
\hline 3 & 6 & - & 1 & 1 & - & - & - & (1) & 9 \\
\hline 4 & 8 & 1 & 1 & 1 & 1 & - & - & - & 12 \\
\hline 5 & 8 & 1 & 3 & 2 & 3 & 1 & - & - & 18 \\
\hline \multirow[t]{2}{*}{6} & - & - & - & 3 & 3 & 4 & 1 & (1) & 12 \\
\hline & 34 & 2 & 6 & 7 & 7 & 5 & 1 & (2) & 64 \\
\hline
\end{tabular}


Table 8. Coverage with reviews during surveillance of $91 \mathrm{~PB}$ patients in the AMFES project who completed MDT before 30 June 1991

\begin{tabular}{lcr}
\hline Coverage & $\begin{array}{l}\text { Reviews done as \% } \\
\text { of required number }\end{array}$ & Patients \\
\hline Nil & None & 14 \\
Very poor & $<30$ & 7 \\
Poor & $30-55$ & 14 \\
Fair & $56-75$ & 25 \\
Good & $76-90$ & 11 \\
Very good & $\geq 91$ & 20 \\
Total & & 91 \\
\hline
\end{tabular}

$1 \cdot 6$ (sd 1.9) at the end of treatment; this difference is highly significant (95\% CI $2 \cdot 1$ to $3 \cdot 3$ ). On average the highest BIs of these patients thus came down $2.7 \log$ points over the notional 2 years of treatment. Of 5 patients with BIs at start ranging from 2 to 6 , the highest $\mathrm{BI}$ did not come down during treatment.

\section{SURVEILLANCE}

Of the 102 PB patients who completed MDT and were put on surveillance, assessments of compliance for 91 patients who had been on surveillance for 1 year or more are shown in Table 8 . For 14 patients $(15 \cdot 4 \%)$ we did not get a single review after RFT. These patients are virtually lost although there is a small chance of future contact. Of the 21 $(7+14)$ patients whose compliance was scored as very poor or poor, 4 had been seen within 12 months of 30 June 1992, so these patients need not yet be considered as lost.

For the $64 \mathrm{MB}$ patients who completed treatment, the period of follow up had been too short to report on their surveillance.

\section{Discussion}

Three aspects of this study population and our preliminary results deserve to be discussed: patient classification and treatment allocation; disability or grades of physical impairment; and some early observations on the outcome of treatment.

\section{PATIENT CLASSIFICATION AND TREATMENT ALLOCATION}

In this study much attention is given to the distinction between $\mathrm{BT}$ and $\mathrm{BL}$ and to a proper choice between the PB and MB treatment regimens. However, in a leprosy control service, arbitrary decisions on the classification of patients are unavoidable at times, given the limitations of both the clinical and laboratory (skin smears) assessment. ${ }^{6}$ As many of our patients were diagnosed rather late, after several years of active disease, some of the BL patients with negative skin smears might have gone, earlier in their 
disease, through a phase* with more BB-BL characteristics and skin-smear positivity. Of the $7 \mathrm{BL}$ patients with $\mathrm{BI}=0$ reported in Table 5,1 is a case of neural leprosy; of the 6 others we did not manage to get repeat skin smears or skin biopsies. Of 3 of them one might doubt - in retrospect, on the basis of recorded clinical characteristics - whether these were not BT cases. The other 3 were most probably true BL patients.

As this study is carried out in an existing leprosy control programme, our patient classification has been influenced by the current practice. In ALERT's leprosy control services 673 new BL patients were registered during the same period. Of the 615 patients for whom skin-smear results were known, as many as $161(26 \%$ !) new BL patients had $\mathrm{BI}=0$. This may reflect shortcomings of the skin-smear service, but amongst these patients are also many with advanced disease of several years' duration, who might have gone through an earlier phase $\dagger$ of $\mathrm{BB}-\mathrm{BL}$ characteristics, but were at the time of diagnosis more BT like in appearance. Although we do not get positive skin smears from these patients, the sheer extensiveness of their disease, usually with more than 20 skin lesions and many nerve trunks affected, makes them eligible for multibacillary treatment. In ALERT's routine services ${ }^{3}$ such smear negative BT/BL? patients who receive $\mathrm{MB}$ treatment are, for the sake of convenience, reported as classified BL. In our study, with only 6 smear negative cases amongst $101 \mathrm{BL}$ patients, we thus give evidence of strict attempts at more accurate classification, but the figures also indicate that this problem has not been resolved fully.

Having to change the classification and/or treatment category for some of the patients is also unavoidable when standard programme procedure requires that a clinical diagnosis is made and anti-leprosy treatment started on the day the patient is seen for the first time. In most leprosy control programmes and also in ALERT's routine programme the frequency of such changes is not reported upon. In our study population we had to make such corrections (Table 2 ) for only $2(1.6 \%)$ of $128 \mathrm{~PB}$ patients and for $13(8.2 \%)$ of $158 \mathrm{MB}$ patients. For the purpose of the relapse incidence study it is reassuring that most of the changes in treatment ( 7 out of 8 ) were from the $\mathrm{PB}$ to the MB regimen. In case of doubt we prefer to prescribe PB treatment, because a change from PB to MB means that the resulting 2-year treatment regimen does not differ much from the standard, whereas if a patient whose definite regimen is $\mathrm{PB}$ did get some months of $\mathrm{MB}$ treatment, this would make a great difference to the composition of that PB patient's 6-month treatment course. Of the 4 patients who were changed from BL to BT, but kept on MB treatment, 3 had more than 20 skin lesions and all had some characteristics suggestive of BL leprosy and signs of extensive involvement of nerve trunks, but repeated skin-smear examinations had remained negative. For 2 of them skin biopsies had been taken and histologically these were considered $\mathrm{BT}$ patients with a $\mathrm{BI}=1$. All 7 patients shifted from $\mathrm{PB}$ to $\mathrm{MB}$ treatment had all been found skin-smear positive within the first few months of treatment; 5 were reclassified as BL, 2 were BT patients with positive smears.

In Ethiopia, MB proportions are much higher than elsewhere in Africa. ${ }^{7,8}$ In our study population, $55 \%$ of the patients were multibacillary. In 2 of the 5 former districts (awrajas) where the AMFES project is carried out, we registered less MB than $\mathrm{PB}$ patients-an $\mathrm{MB}$ proportion of $43.2 \%$ - while in the three other districts the $\mathrm{MB}$ proportion of patients was $57 \cdot 3 \%$. These latter 3 districts belong to the 5 with the highest

\footnotetext{
* We assume that, during several years of disease, before our diagnosis and without specific treatment, these patients' classifications have shifted, through upgrading reversal reactions, from BB (or BL?) to a BT position. † See previous footnote.
} 
MB proportions of the 12 districts of ALERT's leprosy control programme. ${ }^{9}$ We are inclined to consider the observed differences as real, and not to be due to systematic differences in our staff's judgement regarding classification or allocation of treatment category. The possible epidemiological relevance of these findings deserves further investigation.

\section{GRADING OF DISABILITY OR PHYSICAL IMPAIRMENT}

Both in the PB and MB cases - with no significant differences - the disability grades at the time of enrolment (Table 3) were disturbingly high. The fact that $55.6 \%$ of our patients either had a disability grade $1(29 \cdot 0 \%)$ or grade $2(26.6 \%)$ is a very distinct feature of this study population, by which our patients differ greatly from others described in a similar study in Malaw $\mathrm{i}^{10}$ and in reports on patients in Asia. ${ }^{11-13}$ The paucibacillary patients of the study in Malawi, both in the routine LCP services and in the Karonga District with frequent active case-finding surveys, were on average detected in a much earlier stage of the disease. Of their 503 PB patients, $272(54 \cdot 1 \%)$ had at diagnosis a single skin lesion, against only 2 of our $127 \mathrm{~PB}$ patients $(1 \cdot 6 \%)$, and 305 $(60.6 \%)$ of their 503 patients had no palpably enlarged nerves, compared with only $33 /$ $128(25 \cdot 8 \%)$ in our PB patients.

For our study on the incidence of leprosy reaction and neuritis, ${ }^{14}$ we thus deal with a study population which at the time of diagnosis and start of MDT obviously had already gone through several spells of such events.

Grading the disability of a patient by giving that patient the highest of the 6 grades of 2 eyes, 2 hands and 2 feet, has been commented upon extensively by several authors ${ }^{15-17}$ as far too crude a way of characterizing the condition of a patient. The use of a disability index as proposed in 1971 by Bechelli \& Dominguez, ${ }^{18}$ would partly solve that problem. The indices they proposed-unfortunately presenting options for three different formulas: DI(1), DI(2) and DI(3), with different levels of complexity-have never been widely used.

Brandsma et al. ${ }^{16}$ have recently pointed out which important distinctions should be made when speaking about 'disability' and that much of what we term disability should rather be referred to as physical impairment. The WHO-recommended 'disability grade' commonly used for leprosy patients indicates in fact the presence of physical impairment. The more informative sum score of the disability grades of 4 extremities proposed here (Table 4) is, therefore, more correctly termed a 'patient score of physical impairment for hands and feet', shortened to 'HF-impairment score'.

With the relative success of the present antibacterial therapy and less fear of problems with relapse after MDT, prevention of disability is now drawing much more attention than 5-10 years ago. ${ }^{19}$ Accurate scoring of physical impairment thus becomes more needed. For a detailed monitoring of a patient's condition over time, e.g. for the evaluation of neuritis treatment, we consider the HF-impairment score, though much more informative than the conventional disability grading, still not sensitive enough.

It is one of the objectives of the AMFES project to develop a more appropriate scoring system of nerve function as indicator of physical impairment and disability, for use in leprosy control programmes. The challenge is to develop a score that is sensitive enough to distinguish relevant improvement or deterioration but simple enough to be used by paramedical field staff. 
OUTCOME OF TREATMENT

Regarding the effectiveness of the MDT regimens against Mycobacterium leprae, the study on incidence of relapse will need many more years of follow up. So far no relapse has been observed.

The fall in bacterial index of skin smears of MB patients (Table 7) - for this group more than one log point per year of treatment - deserves to be analysed further; also in relation to classification. This will be reported upon when more data have been collected. With $28(45 \cdot 2 \%)$ of 62 patients still skin-smear positive at the end of the 2-year MDT course, of whom $13(21.0 \%)$ still had a BI of 4 or more, further monitoring of the fall of the BI during surveillance will be an obvious feature of the relapse study. Eventually this should provide data to compare the fall of BI in skin smears for the periods during and af ter treatment.

At this stage of this long-term study, an important outcome of treatment to reflect upon is loss to follow-up. So far, the loss of patients during the treatment phase has amounted to approximately $20 \%$, with no difference between PB and MB patients. For the short treatment period of the PB patients, the MDT completion rate of $79 \cdot 7 \%$ in our series is disappointingly low. In ALERT's routine programme the average treatment completion rate of $91 \%$ for PB patients over the first 6 years (1983-88) of experience with MDT, is much better. However, for the years 1989-91, the routine programme also saw a considerable deterioration, with the average completion rate coming down to $82 \% .{ }^{9}$ We assume that this deterioration was mainly due to general factors not particularly related to the leprosy control services, i.e. the economic and security situation in the country.

The $20 \%$ loss of patients during treatment and the not too good coverage of patients during surveillance so far, does not make this an ideal setting for a longitudinal study on incidence of leprosy reactions, neuritis and relapse. This evaluation project has the disadvantages of a long-term study carried out in the setting of a routine service programme. On top of that we have had to cope with specifically difficult circumstances caused by the recent internal war and its related disturbances. For evidence that, despite such adverse conditions, determined field staff are able to collect interesting data on what happens to patients over several years, the reader is referred to Part II.

\section{Acknowledgments}

We gratefully acknowledge the contributions to the research protocol made by the late Han Huikeshoven and by Daan Mulder, the organizational support in planning given by Marijke Becx-Bleumink, then ALERT's Director of Leprosy Control, and advice given in the past few years by Jorg M. Pönnighaus, Daan Mulder and the Medical Advisory Committee of ALERT.

Data management was originally designed and organized by the late Wim 't Mannetje. For the actual data collection we do express our appreciation for the steady care to patients and records by the leprosy control supervisors and health assistants who form the backbone, hands and feet of the programme.

The project is financed by ILEP as a joint project of various associations coordinated by NSL, the Netherlands Leprosy Relief Association. 


\section{References}

1 WHO Study Group. Chemotherapy of leprosy for control programmes. TRS 675; Geneva, 1982.

2 ALERT. Manual for implementation of MDT. 3rd rev. ed. ALERT, Addis Ababa, 1990.

3 Jopling WH. A practical classification of leprosy for field workers. Lepr Rev, 1981; 52: 273-4.

${ }^{4}$ Rowan KM, Byass P, Snow RW. On-line tropical epidemiology - a case-study from the Gambia. Meth Inform Med, 1987; 26: 73-6.

5 World Health Organization. A guide to leprosy control. 2nd ed. 1988. WHO, Geneva.

${ }^{6}$ Becx-Bleumink M. Allocation of patients to paucibacillary or multibacillary drug regimens for the treatment of leprosy: a comparison of methods based mainly on skin smears as opposed to clinical methods; alternative clinical methods for classification of patients. Int J le pr, 1991; 59: 292-303.

7 Berhe D, Haimanot RT, Tedla T, Taddesse T. Epidemiological pattern of leprosy in Ethiopia: a review of the control programmes. Lepr Rev, 1990; 61: 258-66.

${ }^{8}$ Cap JA. The epidemiological situation in Africa. Lepr Rev, 1981; 52 Suppl 1: 53s-60s.

9 ALERT. Annual reports leprosy control, 1983-92. ALERT, Addis Ababa.

10 Boerrigter G, Ponnighaus JM, Fine PE. Preliminary appraisal of a WHO-recommended multiple drug regimen in paucibacillary leprosy in Malawi. Int $J$ Lepr, 1988; 56: 408-17.

11 Smith WCS. The epidemiology of disability in leprosy including risk factors. Le pr Rev, 1992; 63 Suppl: 23s$30 \mathrm{~s}$.

12 Smith WCS, Parkhe SM. Disability assessment as a measure of progress in leprosy control. Lepr Rev, 1986; 57: 251-9.

13 Keeler R, Ryan MA. The incidence of disabilities in Hansen's disease after the commencement of chemotherapy. Lepr Rev, 1980; 51: 149-54.

14 Rijk AJ de, Shibru Gabre, Byass P. Theodroes Berhanu. Field evaluation of WHO-MDT of fixed duration, at ALERT, Ethiopia: the AMFES project. Part 2: Reaction and neuritis during and after MDT in PB and MB leprosy patients. Lepr Rev, 1994; 65: 320-32.

15 Watson JM. WHO disability grading. Letter to the editor. Lepr Rev, 1985; 56: 172-5.

16 Brandsma JW, Heerkens YF, Lakerveld-Heyl K, Mischner-van Ravensberg CD. The international classification of impairments, disabilities and handicaps in leprosy control projects. Lepr Rev, 1992; 63: 337-44.

17 Ponnighaus Ita M, Boerrigter G, Fine PEM, Ponnighaus JM. Disabilities in leprosy patients ascertained in a total population survey in Karonga District, Northern Malawi. Lepr Rev, 1990; 61: 366-74.

18 Bechelli LM, Martinez Dominguez V. Disability index for leprosy patients. Bull WHO, 1971; 43: 709-13.

19 Rose P, Waters MFR. Reversal reactions in leprosy and their management. Editorial. Lepr Rev, 1991; 62: $113-21$. 